\title{
Effect of Applying Nursing Interventions for Preventing Pressure Ulcers among Hospitalized Geriatric Patients
}

\author{
Fatima Adnan Hallaj, Assistant Professor \\ Gerontological Nursing, Faculty of Nursing, Tishreen University-Syria
}

\begin{abstract}
Although there is extensive published information on the prevalence of pressure ulcers in many countries of the world, yet there is a lack of researches concerning the application of nursing interventions for their prevention in hospitals. Objective: Determine the effect of applying nursing interventions for preventing pressure ulcers among hospitalized geriatric patients. Setting: The study was carried out in Tishreen University Hospital, Lattakia, Syria. Subjects: The study subjects comprised 40 hospitalized geriatric patients. These were divided equally into two groups: study and control. Each group comprised 20 elders. Elders in the control group were left to the hospital routine while those in the study group were subjected to nursing interventions for two weeks. The applied nursing interventions include reposition schedule, use pillows to protect bone prominences, proper bed making twice daily, prevention of skin moisture, adequate fluid intake, care for elders' hygiene and use cream on bone prominences. Tools: Three tools were used for data collection: the sociodemographic and clinical structure interview schedule, Skin assessment observation check list and the Braden scale for predicting pressure ulcer risk. Results: The implemented nursing interventions had a positive effect in preventing the development of pressure ulcer among elders' in the study group where the majority of the patients showed no pressure ulcers or no sign of pressure ulcer after two weeks while pressure ulcers were observed among more than two thirds of the patients in the control group. Conclusion: The program succeeded in preventing the development of pressure ulcers. Recommendations: Hospitals' policy should enforce the application of nursing intervention measures to prevent the occurrence of pressure ulcer.
\end{abstract}

Keywords: Geriatric patients; Pressure ulcers; Nursing interventions for preventing pressure ulcers.

\section{Introduction}

Pressure ulcer is "a localized injury to the skin and/or underlying tissue usually over a bony prominence, as a result of pressure, or pressure in combination with shear and/or friction" ${ }^{, 1,2)}$. Evidence suggests that pressure ulcers can arise after only a few hours of immobility-induced pressure $^{(3,4)}$. Unrelieved pressure results in damage to underlying soft tissue when the tissue is compressed between a bony prominence and external surface over a prolonged period of time. The compression of soft tissue interferes with the tissue's blood supply, leading to vascular insufficiency, tissue anoxia, and cell death. Pressure ulcers can develop within 24 hours of the initial pressure but take as long as a week to present themselves. The first tissues to die are those nearest to the bone, and as the pressure and anoxia continue, the remaining layers of tissue begin to $\mathrm{die}^{(1,2)}$. The skin is the last to die. The damage resembles an iceberg, with a smaller amount of damage visible at the surface and a large amount of damage below the surface. Pressure ulcers usually occur over bony prominences such as the sacrum, ischium, heel, and trochanter, where there is less tissue to compress. Pressure ulcers are graded or staged to classify the degree of tissue damage ${ }^{(5,6)}$.

Advanced age has been documented as a major contributing factor to the development of pressure ulcers. With aging, local blood supply to the skin decreases, epithelial layers become flattened and thin, subcutaneous fat decreases, and collagen fibers loose elasticity. These changes in aging skin and the resultant lowered tolerance to hypoxia may enhance pressure- 
ulcer development in older persons. Other factors such as dry and scaly skin, malnutrition, low body mass index, and increased skin moisture e.g. in case of incontinence (urinary and fecal) also contributes to the tissue breakdown ${ }^{(3,4,7)}$. A number of risk factors may also predispose to the development of pressure ulcers including black race, impaired sensory perception or cognition, and specific comorbidities that affect circulation such as diabetes mellitus or peripheral vascular disease (congestive heart failure, hypotension, and stroke), or anemia. These factors put geriatric patients particularly at high risk. But the greatest risk factor to the formation of pressure ulcers is the loss of independent mobility ${ }^{(8-10)}$.

Pressure ulcers hence have detrimental physical, social and functional consequences for older adults, health services and the community. The development of pressure ulcers can lead to several complications as they are often associated with pain and can contribute to decreased function or lead to infection, cellulitis and osteomyelitis and is associated with increased length of hospitalization and depression. Treatment of pressure ulcers are costly. As well in some cases, pressure ulcers may be difficult to be successfully treated with decreased wound healing despite surgical and other invasive treatments. In fact, the mortality rate has been noted to be as high as $60 \%$ for those older persons who develop a pressure ulcer within one year of hospital discharge ${ }^{(11-13)}$.

Pressure ulcers remain a significant problem in hospitals as well as in domestic and community settings. In hospitals, the incidence rates ranged from $1 \%$ to $30 \%^{(1,2)}$. A prevalence of $23.9 \%$ was reported form University Hospitals in Sweden ${ }^{(14)}, 28.7 \%$ in Dutch Intensive Care Units and $8.9 \%$ in Iceland $^{(15,16)}$. A review of all available data from prevalence studies of pressure ulcers conducted over a 13-year period indicated that $26 \%$ of patients admitted in Canadian Health Care settings developed pressure ulcers $^{(17)}$. Each year, more than 2.5 million people in the United States develop pressure ulcers. In 2006, pressure ulcers were reported in more than 500,000 hospital stays. Nearly 60,000 United States hospital patients are estimated to die each year from complications due to hospital-acquired pressure ulcers, and the total cost for treatment of pressure ulcers in the United States is estimated to be $\$ 11$ billion per year ${ }^{(10,18)}$. A study carried out in Alexandria, Egypt 2009 found that $38.7 \%$ and $33.3 \%$ of elderly home residents had moderate and high risk of pressure ulcers respectively ${ }^{(19)}$. The prevalence of pressure ulcers among hospitalized patients in Syria has been sparingly reported.

Despite a growing awareness of the dramatic impact of pressure ulcers on quality of life, increase cost of hospital care, and being a major cause of morbidity, mortality, the frequency of pressure ulcers among geriatric patients has not decreased in recent years ${ }^{(20)}$. Although largely preventable, pressure ulcers affect millions of people worldwide and consume billions of dollars in health care spending. This largely preventable patient safety problem is recognized universally as one of the five most common causes of harm to patients, and is increasingly being described as an indicator of the quality of care provided by health care organizations. Thus, pressure ulcer prevention presents an important challenge in hospitals ${ }^{(21-23)}$.

Recently, attention has been focused on the problem of pressure ulcers in hospitals as a preventable adverse outcome. There is evidence supporting the effectiveness of some pressure ulcer preventive measures, and national clinical guidelines for prevention of pressure ulcers were developed. These include protecting the skin from injury by limiting pressure and reducing friction, taking care of skin and protecting bone prominences, safeguarding skin from moisture, repositioning schedule, and maintaining the ability to move ${ }^{(24-26)}$. 
Success in preventing pressure ulcers through proper nursing depends on early identification of risks for their development and regular careful assessment of skin over bony prominences ${ }^{(1,2)}$. In this respect, nurses play an important role in preventing the occurrence of pressure ulcers through the early identification of warning signs, maintaining skin dry and emphasizing the importance of early ambulation of the geriatric patients to avoid pressure on bony prominences and improve circulation.

\section{Aim of the Study}

The aim of the study is to determine the effect of applying nursing interventions for preventing pressure ulcers among hospitalized geriatric patients.

\section{Research Hypothesis:}

The application of nursing intervention measures will prevent the occurrence of pressure ulcers among hospitalized geriatric patients.

\section{Materials and Method}

\section{Materials}

Design: Quasi experimental study.

Setting: The study was carried out in the all medical units (7 units) in Tishreen University Hospital, Lattakia, Syria. This hospital is affiliated to Tishreen University in Lattakia, which is under the Ministry of Higher Education. It is a teaching hospital and accepts patients from all ages.

Subjects: The study subjects comprised 40 geriatric patients admitted to the previously mentioned settings and fulfilling the following criteria: age 60 years and more, able to move, with no pressure ulcer at the time of admission, BMI (18.5 to 29.99), and whose condition required their stay in the hospital for at least two weeks according to doctor opinion and agree to participate in the study. These patients were divided equally into two groups: study and control.
Elders excluded are those with: bowel or urinary incontinence, anemia, diabetes mellitus, and peripheral vessel diseases (chronic ischemia).

Tools: Three tools were used to collect the data:

\section{Tool I: Socio-demographic and clinical} data structured interview schedule

It was developed by the researcher after thorough review of literature and included the following data:

1. Data about the elders': Socio demographic characteristics such as age, gender, social status, level of education.

2. Health history: presence of chronic diseases and medication used.

3. Skin care: number of showers per week, type of soap used.

4. Amount of fluid intake / day and nutrition.

5- BMI.

Tool II: Skin assessment observation check list

It was developed by Boston University Research Team (2016) ${ }^{(27)}$ to assess the condition of the skin in order to identify any abnormality over bony prominence such as: change in the skin temperature (hotness), change in the skin color(redness), skin moisture (if the skin is wet or dry), skin turgor (edema), and skin intact (integrity).

Tool III: Braden scale for predicting pressure ulcer risk

This scale was developed by Barbara Braden and Nancy Bergstrom (2012) ${ }^{(28)}$, and used to identify patients at-risk for pressure ulcers. It is composed of six questions that investigate the elder's sensory perception, skin moisture, activity level, mobility, usual food intake, and exposure to friction and shear.

The maximum score is 23 (the total scores range from 6 to 23). The total score divides the risk to these categories: 


$$
\begin{array}{ll}
15-18 & \text { Mild risk } \\
12-14 & \text { Moderate risk } \\
<12 & \text { High risk }
\end{array}
$$

The Braden scale has demonstrated excellent sensitivity and specificity in hospitals. Also it has been validated in many research studies with elderly people in hospital and nursing home. Studies have demonstrated internal consistency and interobserver reliability $(\mathrm{r}=0.89)^{(29-31)}$.

\section{Development of the nursing interventions:}

This was developed by the researcher after thorough review of literature. It included reposition schedule, use pillows to protect bone prominences, proper bed making twice daily (tight sheets to prevent wrinkles), prevention of skin moisture, adequate fluid intake, care for elders' hygiene and use cream on bony prominences. The nursing intervention was applied to each elderly person in the experimental group for two consecutive weeks.

\section{Method}

1. Verbal official approvals from the competent authorities to carry out the study were obtained.

2. Arabic translation of (Braden scale for predicting pressure ulcer risk) was done by the researcher and validated by five experts in the field of study. Then, it was tested for its reliability on 20 elders using test retest method (after 2 weeks). Spearman's correlation coefficient for Braden scale was $r=0.96$.

3. Informed consent from elders to participate in the study was obtained after explanation of the study purpose.

4. A pilot study was conducted on five elders selected from University Tishreen Hospital to test the study tools. The necessary modifications were made based on the results of the pilot study. These elders were excluded from the study.

5. Assessment of all elders upon admission to the study settings was done in order to identify those fulfilling the study criteria. During the study period 223 elderly were assessed, 73 had already pressure ulcers and were excluded from the study. From the remaining 150 , the researcher selected 40 elders. These were divided randomly into two groups; study and control groups using systematic random technique. The rest either refused to participate in the study or were discharged before two weeks from the hospital.

6. Each elder included in the study was assessed individually by the researcher to determine skin status before the implementation of the interventions using tool II and III.

7. Elders in the control group were left to their hospital routine care while those in the study group were subjected to the applied nursing interventions.

\section{Nursing interventions:}

The researcher greeted the elder, introduced herself, gave a brief summary about the benefits and components of the nursing interventions and asked the elder to cooperate for his benefit. The following interventions were applied for each elder individually:

- Changing the position every hour (consult with doctor for the right position).

- $\quad$ Put the head of bed at 300 .

- Use pillows or dressings to prevent skin to skin contact and to protect bone prominences.

- Make the bed twice daily (tight bed sheets under the mattress to prevent wrinkles), and change the sheets when drenches. 
- Give and make sure that the patient takes adequate fluid daily $(2.5 \mathrm{~L})$ whether orally or through IV infusions if needed.

- Nutrition (the meals provided by the hospital include all the nutritional requirements).

- Skin hygiene: keep the skin clean and dry; and use cream (pantinol) once per day on bony prominences.

- Encourage the patient to walk either in the room or in corridor daily for 15 minutes (begin with 5 minutes and increased according to the elder's tolerance).

\section{Evaluation of the nursing interventions:}

After the implementation of the nursing interventions for two weeks, each of the participants in the two groups was reassessed (4 times with three days interval) in order to predict the development of pressure ulcer using tool II "Skin assessment observation check list" and tool III "Braden scale for predicting pressure ulcer risk".

Data collection started from the first of June 2017 to the end of October 2017.

\section{Ethical considerations:}

Informed consent was obtained from each patient. Privacy and confidentiality of the collected data was assured. Each elderly was informed about his right to withdraw from the study without penalties.

\section{Statistical Analysis}

- Statistical analysis was performed using Stata version 18 (IBM corporation).

- A chi-square test was used to study the relationship between two categorical variables.

- The t-test was used to compare differences between continuous variables.

- Descriptive statistics using means (standard deviations) for continuous data and frequencies (\%) for categorical data were calculated.

- P value less than 0.05 was considered to be statistically significant.

\section{Limitations of the study:}

- Some geriatric patients (from both groups) were discharged from the hospital before two weeks. Their number amount to nine elders. These were replaced by others fulfilling the study inclusion criteria.

- Three elders withdrew from the study and refused to complete the sessions. These were replaced by other elders to maintain the sample size.

\section{Results}

Table (1) shows the socio-demographic characteristics and health profile of the geriatric patients. No significant difference was found between the study and control groups with respect to socio-demographic characteristics. The age of the elders in both groups ranged from 65 to 87 years. The mean age of the study group is $74.5 \pm 9.1$ years and that of the control group is $73.5 \pm 9.4$ years. Married elders constituted $60.0 \%$ and $70.0 \%$ of the study and control groups respectively. Females included in the study groups were $50.0 \%$ compared to $45.0 \%$ in the control group. As regards level of education those with basic education were $40.0 \%$ in the study group and $60.0 \%$ in the control. The rest of the study group $(30.0 \%)$ had either secondary or university education compared to $10.0 \%$ and $30.0 \%$ respectively for the control group.

No significant difference was found between the study and control groups as regards their health profile. It appears from the table that $70.0 \%$ of the study group and $75.0 \%$ of the control group reported having cardiovascular diseases. Musculoskeletal disorders were reported by $55.0 \%$ and $60.0 \%$ of the study and control groups respectively. Respiratory disorders were observed more among those in the study 
group $(20.0 \%)$ compared to only $5.0 \%$ in the control group.

Antihypertensive drugs were the most common drugs consumed by the elders. It was used by as much as $75.0 \%$ of the study group and $70.0 \%$ of the control group. Anticoagulant are being used by $(45.0 \%)$ of each of the two groups; anti-inflammatory and analgesics drugs were used by $20.0 \%$ of the study group and $15.0 \%$ and diuretics were used by $(10.0 \%)$ for each of the two groups.

The BMI of each of the two groups were within normal range. The mean BMI of the study group was $21.8 \pm 2.3$ and that of the control group was 23.2 \pm 3.3 .

Table (2) assessing the skin condition around bony prominent areas after two weeks of the implementation of nursing interventions the table shows that in the study group none of the subjects showed any change either in the skin temperature or moisture or turgor or its intact. Change in skin color (redness) was observed in only 2 $(10.0 \%)$ of the study subjects. While in the control group $70.0 \%$ of the subjects showed change either in the skin temperature (hotness), $70.0 \%$ in skin color (redness), and $70.0 \%$ had skin dryness. Edema and skin abrasion were observed in $10.0 \%$, and $5.0 \%$ respectively. The differences are statistically significant $(\mathrm{P}=0.0001)$ between the two groups.

Table (3) shows the mean score of Braden Scale of the geriatric patients in both groups before and two weeks after the implementation of the nursing interventions. It appears from the table that the mean score decreased from $21.85 \pm 1.04$ on admission to reach $19.95 \pm 1.96$ among the study group after 2 weeks while in the control group it decreased from $20.80 \pm 1.24$ to $15.30 \pm 4.03$ during the same period. The difference between the mean change in the two groups is statistically significant $(\mathrm{P}=0.0004)$.

Table (4) applying the Braden Scale on the study group after two weeks from the implementation of nursing interventions the table shows $90.0 \%$ of the elders the study group showed no risk and only $2(10.0 \%)$ had mild risk. While in the control group $30.0 \%$ of the elders showed no risk, $40.0 \%$ mild risk, $20.0 \%$ moderate risk, and $10.0 \%$ high risk.

Table (5) shows the distribution of geriatric patients according to the area affected by pressure ulcer after the implementation of nursing interventions. When reassessing the skin condition around bony prominent areas after two weeks from the implementation of nursing interventions the table shows that for the study group the sacrum was the only affected area. This was observed in only $2(10.0 \%)$ of the study subjects. On the other hand, among the control group ulcers were observed on all bony prominences namely sacrum $20.0 \%$, heels $25.0 \%$, buttocks $20.0 \%$, greater trochanter $25.0 \%$, and lateral malleoli $15.0 \%$.

Table (6) shows the distribution of geriatric patients according to the stage of the pressure ulcers in both study and control groups after the implementation of nursing interventions. The table shows that only 2 of the study group developed pressure ulcer of stage I compared to $50.0 \%$ of those in the control group. Stage II was present in $15.0 \%$ and stage III in $5.0 \%$ of the control group compared to none of the study group.

\section{Discussion}

Although largely preventable, pressure ulcers remain a serious problem affecting millions of people worldwide. This largely preventable problem is recognized universally as one of the five most common causes of harm to geriatric patients as it has detrimental physical, social and functional consequences $^{(10)}$. It is increasingly being described as an indicator of the quality of care provided by health care organizations ${ }^{(7)}$. So, the aim of the study was to determine the effect of nursing interventions on preventing pressure ulcer among hospitalized geriatric patients. 
The applied nursing interventions succeeded in preventing the occurrence of pressure ulcers among geriatric patients in the study group during the study period where all subjects except two showed no risk of pressure ulcers at the end of the study period (table 4, 5, 6). It is worth mentioning that the two patients who showed redness on the sacrum region suffer from musculoskeletal disorders which made their movement difficult and painful. As well, this hindered their effective compliance with the applied nursing interventions. This, in turn, might have increased their risk to develop pressure ulcer. This supports other studies conducted in the University Hospitals in Nigeria $(2013)^{(32)}$ where only $3.22 \%$ developed pressure ulcer and in Lebanon (2014) $)^{(33)}$ which reported that the applied nursing interventions (which included bed making, changing patient's position, nutritional support, and skin care) was effective in decreasing the prevalence of pressure ulcers where only $5.23 \%$ had pressure ulcers. Contrary to the results of the present study (table 2), higher percentages were reported from other studies carried out the University Hospitals in Sweden ${ }^{(34)}(23.9 \%)$, from Canadian Health Care Settings ${ }^{(35)}$ (26.0\%), from Philadelphia and Pennsylvania university hospitals ${ }^{(19)}(68.0 \%)$, and from assisted living facilities (elderly homes) Alexandria, Egypt $^{(35)}(45.3 \%)$. These differences in prevalence rates may be attributed to the different health care settings and study designs.

As regards the stage of pressure ulcer, a study in $\mathrm{USA}^{(8)}$ reported that nearly two thirds of the studied subjects developed pressure ulcers of stage II. In the present study, only two geriatric patients among the study subjects developed pressure ulcer of stage I, while among the control group pressure ulcers of either stage I, II or III were observed among the majority (table 6). The most common sites affected were the heels, greater trochanter, sacrum and the ischium and the lateral malleoli (table 5). This may be because of the hospital care routine which neglects the importance of skin care to prevent pressure sores and infection as the skin is the first line of defense of the body. The majority of geriatric patients in the control group had poor personal hygiene. Poor skin care such as cleaning, drying and application of lubricant on bony prominences which help to protect the skin particularly for geriatric patients whose skin is fragile and easy to break. The same findings were reported in other studies ${ }^{(36,32)}$, but the most common anatomical locations of pressure ulcer were nearly a half reported in the buttocks, and less than one fifth present on the sacrum, greater trochanter, and heels ${ }^{(32)}$.

Reassessing the skin around bony prominent areas two weeks after of the implementation of the nursing interventions, it was noticed that the nursing interventions succeeded in protecting the skin where no one in the study group had either change in the skin temperature or moisture or turgor or intact expect two, while in the control group all subjects showed change either in the skin temperature (hotness), or color (redness), or dryness. Also, edema and abrasion were observed in $15.0 \%$ of the geriatric patients in the control group (table 2). Since all patients in the two groups had no risk of pressure ulcer on admission to the hospital the risk for pressure ulcer increased significantly after two weeks of the implementation of the nursing interventions among patients in the control group compared to those in the study group where the majority still have no risk (table $\mathbf{3}, \mathbf{4}$ ). This may be attributed to the routine hospital care which do not emphasize the importance of assessing elders' skin regularly to detect early those at risk for developing pressure ulcers and do not institute appropriate measures to prevent this problem. These results are in line with other studies ${ }^{(8,32)}$.

It was noted that the applied nursing interventions succeeded in preventing the occurrence of pressure ulcers where the frequent change of elders' position every 
hour reduces pressure, friction, and shear damage, and minimized the prolonged pressure on bony prominences, thereby maintaining an adequate supply of oxygen and nutrients to the area and therefore preventing tissue death. The same was reported in another study done in USA $(2007)^{(36)}$ which found that repositioning the patient shifts or relieves the pressure on the susceptible areas, and diminishes the risk of pressure ulcer development. Another study reported that repositioning is believed to reduce the length of time that the tissue is under pressure and decreases the likelihood of the development of pressure ulcer ${ }^{(37)}$. Raising the head of the bed to $30^{\circ}$ also helped to prevent impairment of oxygen supply to the skin.

Moreover, keep the skin clean and dry can lower the risk of developing pressure ulcers. In addition, massage and use cream daily around bone prominences prevent skin damage. This supports other studies done in USA $(2007)^{(36)}$ and Lebanon $(2014)^{(33)}$ where the majority of the patients with documented skin care had protective dressings applied over bony prominences which may have been a protective factor in preventing the development of pressure ulcers. Furthermore, mobility and walking in the room or corridor daily according to the elder's tolerance increases blood circulation which brings oxygen, nutrients, vitamins and minerals that support growth of cells and tissue. These help in maintain the integrity of the skin and prevent pressure ulcer. As well, adequate fluid intake daily helps in the development of new cells and growth of new tissue where body uses water to carry nutrients to the cells. The same observation was reported in another study done in USA (2007) ${ }^{(36)}$. Also, the use of pillows and dressings help to prevent skin to skin contact and to protect bony prominences where it minimizes shear and friction damage and reduces pressure. The same findings were found in USA $(2007)^{(36)}$ which reported that the use of pillows and blankets reduce or even relieve the pressure that the patient's body weight exerts on the skin and subcutaneous tissues.

\section{Conclusion}

It can be concluded from the study that the application of different nursing interventions resulted in positive decrease in the incidence of pressure ulcers leading to either their prevention or at least decrease the risk of their development.

\section{Recommendations}

1- Nurses should assess elders' skin on admission to the hospitals in order to detect early those at risk for developing pressure ulcers, and to institute appropriate measures to prevent their occurrence.

2- Elders should be motivated and encouraged by nurses to remain active. Also, nurses should encourage elders and/or help them to change their position every one hour to reduce pressure, friction and shear damage on bony prominences.

3- In-service training for nurses about measures required to prevent the occurrence of pressure ulcers, emphasizing the importance of their application in their daily work.

4- Provide the hospitals with the necessary supply required by nurses to achieve their aim in preventing pressure ulcer formation. 
Table (1): Distribution of geriatric patients in the study and control groups according to their socio-demographic characteristics and health profile

\begin{tabular}{|c|c|c|c|c|c|}
\hline \multirow{2}{*}{$\begin{array}{l}\text { Socio-demographic Characteristics and } \\
\text { Health Profile }\end{array}$} & \multicolumn{2}{|c|}{ Study group } & \multicolumn{2}{|c|}{ Control group } & \multirow[b]{2}{*}{ Significan } \\
\hline & $\begin{array}{l}\text { NO. } \\
\text { n=20 }\end{array}$ & $\begin{array}{c}\% \\
100\end{array}$ & $\begin{array}{l}\text { NO. } \\
\text { n=20 }\end{array}$ & $\begin{array}{c}\% \\
100\end{array}$ & \\
\hline $\begin{aligned} \text { - Age (in years): } \\
\text { - } \quad 60- \\
\text { - } \quad 70- \\
\text { - } \geq 80 \\
\end{aligned}$ & $\begin{array}{l}10 \\
5 \\
5\end{array}$ & $\begin{array}{l}50.0 \\
25.0 \\
25.0\end{array}$ & $\begin{array}{l}8 \\
6 \\
6\end{array}$ & $\begin{array}{l}40.0 \\
30.0 \\
30.0\end{array}$ & $\mathrm{P}=0.817$ \\
\hline Mean \pm SD & \multicolumn{2}{|c|}{$73.5 \pm 9.4$} & \multicolumn{2}{|c|}{$74.5 \pm 9.1$} & $\mathrm{P}=0.7346$ \\
\hline $\begin{aligned} \text { - Sex: } & \\
\bullet & \text { Female } \\
\bullet & \text { Male }\end{aligned}$ & $\begin{array}{l}10 \\
10\end{array}$ & $\begin{array}{l}50.0 \\
50.0\end{array}$ & $\begin{array}{c}9 \\
11\end{array}$ & $\begin{array}{l}45.0 \\
55.0\end{array}$ & $\mathrm{P}=0.752$ \\
\hline $\begin{array}{cl}\text { - Social status: } \\
\bullet & \text { Married } \\
\bullet & \text { widowed } \\
\end{array}$ & $\begin{array}{c}12 \\
8\end{array}$ & $\begin{array}{l}60.0 \\
40.0\end{array}$ & $\begin{array}{c}14 \\
6 \\
\end{array}$ & $\begin{array}{l}70.0 \\
30.0\end{array}$ & $\mathrm{P}=0.507$ \\
\hline $\begin{array}{l}\text { - Educational Level: } \\
\text { - } \text { Basic } \\
\text { - } \text { Secondary } \\
\text { - } \quad \text { Higher education } \\
\end{array}$ & $\begin{array}{l}8 \\
6 \\
6\end{array}$ & $\begin{array}{l}40.0 \\
30.0 \\
30.0\end{array}$ & $\begin{array}{l}12 \\
2 \\
6\end{array}$ & $\begin{array}{l}60.0 \\
10.0 \\
30.0\end{array}$ & $\mathrm{P}=0.247$ \\
\hline $\begin{array}{c}\text { - Diseases: \# } \\
\text { - } \quad \text { Cardiovascular disease } \\
\text { - Musculoskeletal disorders } \\
\text { - } \quad \text { GIT disorders } \\
\text { - } \\
\end{array}$ & $\begin{array}{c}14 \\
11 \\
1 \\
4\end{array}$ & $\begin{array}{c}70.0 \\
55.0 \\
5.0 \\
20.0\end{array}$ & $\begin{array}{c}15 \\
12 \\
0 \\
1\end{array}$ & $\begin{array}{c}75.0 \\
60.0 \\
0.0 \\
5.0\end{array}$ & $\begin{array}{l}P=0.723 \\
P=0.749 \\
P=0.311 \\
P=0.151\end{array}$ \\
\hline $\begin{array}{l}\text { - Drugs: \# } \\
\text { - Anti hypertensive } \\
\text { - Anicoagulant } \\
\text { - Digitals } \\
\text { - Diuretics } \\
\text { - Anti-inflammatory and analgesics } \\
\text { - Bronchodilators } \\
\text { - Anti histaminics } \\
\end{array}$ & $\begin{array}{c}15 \\
9 \\
1 \\
2 \\
4 \\
4 \\
2\end{array}$ & $\begin{array}{c}75.0 \\
45.0 \\
5.0 \\
10.0 \\
20.0 \\
20.0 \\
10.0\end{array}$ & $\begin{array}{c}14 \\
9 \\
1 \\
2 \\
3 \\
0 \\
0\end{array}$ & $\begin{array}{c}70.0 \\
45.0 \\
5.0 \\
10.0 \\
15.0 \\
0.0 \\
0.0\end{array}$ & $\begin{array}{c}\mathrm{P}=0.723 \\
\mathrm{P}=1 \\
\mathrm{P}=1 \\
\mathrm{P}=1 \\
\mathrm{P}=0.677 \\
\mathrm{P}=0.035 \\
\mathrm{P}=0.147\end{array}$ \\
\hline $\begin{array}{l}\text { - BMI: } \\
\text { Mean } \pm \text { SD }\end{array}$ & 21. & 2.3 & 23. & 3.3 & $\mathrm{P}=0.1242$ \\
\hline
\end{tabular}

Table (2): Distribution of geriatric patients in the study and control groups according to their skin condition around bony prominent areas two weeks after the implementation of nursing interventions

\begin{tabular}{|c|c|c|c|c|c|}
\hline \multirow{2}{*}{$\begin{array}{l}\text { Skin condition around bony } \\
\text { prominent areas after two weeks of } \\
\text { the program }\end{array}$} & \multicolumn{2}{|c|}{ Study group } & \multicolumn{2}{|c|}{ Control group } & \multirow[b]{2}{*}{ Significant } \\
\hline & $\begin{array}{c}\text { NO. } \\
\text { n=20 }\end{array}$ & $\begin{array}{c}\% \\
100\end{array}$ & $\begin{array}{l}\text { NO. } \\
\text { n=20 }\end{array}$ & $\begin{array}{l}\text { NO. } \\
\text { n=20 }\end{array}$ & \\
\hline - Skin temperature (hotness) & 0 & 0.0 & 14 & 70.0 & $\mathrm{P}=0.0001 *$ \\
\hline - Skin color (redness) & 2 & 10.0 & 14 & 70.0 & $\mathrm{P}=0.0001 *$ \\
\hline - Skin moisture (wet or dry) & 0 & 0.0 & 14 & 70.0 & $\mathrm{P}=0.0001 *$ \\
\hline - Skin turgor (edema) & 0 & 0.0 & 2 & 10.0 & $\mathrm{P}=0.147$ \\
\hline - Skin intact (integrity) & 0 & 0.0 & 1 & 5.0 & $\mathrm{P}=0.311$ \\
\hline
\end{tabular}

* Significant $\mathrm{P} \leq 0.05$ 
Table (3): Mean score of Braden scale of geriatric patients in the study and control groups on admission and during the follow up period after the implementation of the nursing interventions

\begin{tabular}{||l|c|c|c||}
\hline \multirow{2}{*}{ Braden scale for predicting pressure ulcer risk } & Study group & Control group & \multirow{2}{*}{ P value } \\
\cline { 2 - 4 } & Mean \pm SD & Mean \pm SD & \\
\hline • On admission & $21.85 \pm 1.04$ & $20.80 \pm 1.24$ & $\mathrm{P}=0.0061^{*}$ \\
- Fourth day & $21.40 \pm 1.23$ & $18.65 \pm 3.15$ & $\mathrm{P}=0.0008^{*}$ \\
• One week & $20.75 \pm 1.21$ & $16.40 \pm 3.73$ & $\mathrm{P}=0.0001^{*}$ \\
• Two weeks & $19.95 \pm 1.96$ & $15.30 \pm 4.03$ & $\mathrm{P}=0.0001^{*}$ \\
\hline Mean change \pm SD & $\mathbf{1 . 9 0} \pm \mathbf{1 . 2 5}$ & $\mathbf{5 . 5 0} \pm \mathbf{3 . 9 8}$ & $\mathrm{P}=0.0004^{*}$ \\
\hline \hline
\end{tabular}

* Significant $\mathrm{P} \leq 0.05$

Table (4): Predicting pressure ulcer risk among geriatric patients in the study and control groups using Braden scale after two weeks from the implementation of the nursing intervention

\begin{tabular}{|c|c|c|c|c|c|c|c|c|}
\hline \multirow{3}{*}{ Subjects } & \multicolumn{8}{|c|}{ Predicting pressure ulcer risk after 2 weeks } \\
\hline & \multicolumn{2}{|c|}{ No risk } & \multicolumn{2}{|c|}{ Mild risk } & \multicolumn{2}{|c|}{ Moderate risk } & \multicolumn{2}{|c|}{ High risk } \\
\hline & No. & $\%$ & No. & $\%$ & No. & $\%$ & No. & $\%$ \\
\hline Study group $(\mathrm{n}=20)$ & 18 & 90.0 & 2 & 10.0 & & & & \\
\hline Control group $(\mathrm{n}=\mathbf{2 0})$ & 6 & 30.0 & 8 & 40.0 & 4 & 20.0 & 2 & 10.0 \\
\hline
\end{tabular}

* Significant $\mathrm{P} \leq 0.05$

Table (5): Distribution of geriatric patients in the study and control groups according to the area affected by pressure ulcers two weeks after the implementation of nursing interventions

\begin{tabular}{||l|c|c|c|c||}
\hline \multirow{2}{*}{ Area \# } & \multicolumn{4}{|c||}{ After 2 weeks } \\
\cline { 2 - 5 } & \multicolumn{2}{|c|}{ Study group } & \multicolumn{2}{c||}{ Control group } \\
\cline { 2 - 5 } & $\mathbf{N O .}$ & $\mathbf{\%}$ & $\mathbf{N O .}$ & $\mathbf{\%}$ \\
& $\mathbf{n = 2 0}$ & $\mathbf{1 0 0}$ & $\mathbf{n = 2 0}$ & $\mathbf{1 0 0}$ \\
\hline - Sacrum & 2 & 10.0 & 4 & 20.0 \\
- Heels & Ischium (buttocks) & 0 & 5 & 25.0 \\
- Greater trochanter & 0 & 0.0 & 4 & 20.0 \\
- Lateral malleoli & 0 & 0.0 & 5 & 25.0 \\
\hline
\end{tabular}

\# More than one answer was allowed

Table (6): Distribution of geriatric patients according to the stage of pressure ulcers two weeks after the implementation of nursing interventions among the study and control groups

\begin{tabular}{|c|c|c|c|c|c|c|}
\hline \multirow{2}{*}{ Pressure ulcer stage } & \multicolumn{2}{|c|}{ Study group } & \multicolumn{2}{|c|}{ Control group } & \multicolumn{2}{|c|}{ Total } \\
\hline & $\begin{array}{c}\text { NO. } \\
\mathrm{n}=20\end{array}$ & $\begin{array}{c}\% \\
100 \\
\end{array}$ & $\underset{n=20}{\text { NO. }}$ & $\begin{array}{c}\% \% \\
100\end{array}$ & $\begin{array}{c}\text { NO. } \\
n=40\end{array}$ & $\begin{array}{c}\% \\
100\end{array}$ \\
\hline - $\quad$ No & 18 & 90.0 & 6 & 30.0 & 24 & 60.0 \\
\hline - Stage I & 2 & 10.0 & 10 & 50.0 & 12 & 30.0 \\
\hline - Stage II & 0 & 0.0 & 3 & 15.0 & 3 & 7.5 \\
\hline - Stage III & 0 & 0.0 & 1 & 5.0 & 1 & 2.5 \\
\hline
\end{tabular}




\section{References}

1. National Pressure Ulcer Advisory Panel (NPUAP). Pressure ulcer definition and stage, 2013. Available at: http://www.npuap.org.

2. European Pressure Ulcer Advisory Panel (EPUAP and National Pressure Ulcer Advisory Panel (NPUAP). Treatment of pressure ulcers: quick reference guide. Washington DC: National Pressure Ulcer Advisory Panel, 2009.

3. Baumgarten $\mathrm{M}$, Margolis $\mathrm{D}$, Localio $\mathrm{R}$, Kagan S, Lowe R, Kinosian B, Holmes J, Abbuhl S, Kavesh W, Ruffin A. Pressure ulcers among elderly patients early in the hospital stay. Journal of gerontology: medical sciences 2006; 61(7): 749- 54.

4. Yoshikawa TT, Livesley NJ \& Chow AW. Infected pressure ulcers in elderly individuals. Clin Infect Dis 2002; 35:13901396.

5. Bours GJJW,Halfens RJG, Abu-Saad HH \& Grol RTPM. Prevalence, prevention, and treatment of pressure ulcers: Descriptive study in 89 institutions in the Netherlands. Res Nurs Health 2002; 25:99-110.

6. Ilesanmi RE, Ofi BA, Adejumo PO. Nurses' knowledge of pressure ulcer prevention in Ogun State, Nigeria: results of a pilot study. Ostomy Wound Mange 2012; 58(2): 24- 32.

7. Gender A. Pressure ulcer prevention and management. ARN Journal 2008; 10(2): 89.

8. Rich S, Shardell M, Margolis D, Baumgarten M. Pressure ulcer preventive device use among elderly patients early in the hospital stay. Nurs Res 2009; 58(2): 95104.

9. Bluestein D, Javaheri A. Pressure ulcers: prevention, evaluation, and management. American Family Physician 2008; 78 (10):1186-94.

10. Cuddigan J, Berlowitz DR \&Ayello E. Pressure ulcers in America: Prevalence, incidence and implication for the future: An executive summary of the National Advisory Panel Monograph. Adv Skin Wound Care 2001; 14(4):208-215.
11. Lyder C. Pressure ulcer prevention and management. JAMA 2003; 289(2): 223- 6.

12. Lyder CH, Ayello EA. Pressure ulcers safety issue: patient safety and quality: an evidence- based handbook for nurses. Oregon: Agency for healthcare research and quality, 2008; 1-33.

13. Agency for healthcare research and quality: advancing excellence in health care. Pressure ulcer risk assessment and prevention: comparative effectiveness. AHRQ Publication 2013; 12(13): 17- 20.

14. Gunnigberg L. Risk, prevalence and prevention of pressure ulcers in three Swedish healthcare settings. J Wound Care 2004; 13(7): 286-90.

15. Bours GJ, Laat E, Halfens RJ, Lubbers M. Prevalence, risk factors and prevention of pressure ulcers in Dutch intensive care units: Results of a cross-sectional survey. Intensive Care Med 2001; 27(10): 1599605.

16. Thoroddsen A. Pressure sore prevalence: a national survey. J ClinNurs 1999; 8(2): 170-9.

17. Woodbury MG, Houghton PE. Prevalence of pressure ulcers in Canadian healthcare settings. Ostomy Wound Manage 2004; 50 (10): $22-38$.

18. Melter C. Pressure ulcer assessment and treatment. Wild iris medical education, INC, 2014; 2- 5.

19. Mahrouse R. Prediction of pressure ulcer development among institutionalized elderly. Unpublished Master Thesis. Faculty of Nursing, Alexandria University, 2009.

20. Posthauer M, Banks M, Dorner B, Schols J. The role of nutrition for pressure ulcer management: National Pressure Ulcer Advisory Panel, European Pressure Ulcer Advisory Panel, and Pan Pacific Pressure Injury Alliance White Paper. Advances in Skin \& Wound Care 2015; 28(4): 175- 88.

21. Schnelle J. Pressure ulcer prevention training module. Los Angeles: The Anna 
and Harry Borun Center for Gerontological Research, 2004; 17-24.

22. Berlowitz D, Lukas C, Parker V, Silver J, Logan C, Ayello E, Zulkowski K. Preventing pressure ulcers in hospitals: A toolkit for improving quality of care. Oregon: Agency for healthcare research and quality, 2010; 1-8.

23. Australian Wound Management Association. Pan Pacific Clinical Practice Guidelines for the Prevention and Management of Pressure Injury. Osborne Park, WA: Cambridge Media, 2012.

24. Perry D, Borchert K, Burke S, Chick K, Johnson K, Kraft W, Patel B, Thompson S.Pressure Ulcer Prevention and Treatment Protocol. Institute for Clinical Systems Improvement. 2015. Available at: http://www.icsi.org.

25. Bye K, Buescher D, Sandrick M. never say never: a descriptive study of hospitalacquired pressure ulcers in a hospital setting. Journal of Wound, Ostomy, and Continence Nursing 2012; 39(3): 274-81.

26. Malone J, Mcinnes E, Black N. Clinical practice guidelines: pressure ulcer risk assessment and prevention recommendations. London: Royal College of Nursing, 2001; 14-20.

27. Boston University research team. Comprehensive skin assessment sheet. Boston: Boston University 2016.

28. Braden B. The Braden scale for predicting pressure sore risk: reflections after 25 years. Advances in Skin \& Wound Care 2012; 25(2): 61-3.

29. El-Sharkawy FM, Reda NA. Predicting factors for development of decubitus ulcers in an ICU population. The Alexandria Medical Journal 1997; 39(1): 175-88.

30. Mohamed SS. Predicting pressure ulcer risk: a study of the predictive validity of the Braden Scale at El-kasr El-Aini Hospital. Unpublished Master thesis, Faculty of Nursing: University of Cairo, 2007.

31. Ibrahim YM. Skin care Intervention for pressure ulcer prevention among cardiac surgical patients. ASNJ 2007; 6(1): 1-9.
32. Adegoke BOA, Odole AC, Akindele LO, Akinpelu AO. Pressure ulcer prevalence among hospitalized adults in university hospitals in South-west Nigeria. Wound Practice and Research 2013; 21(3): 128-34.

33. Mallah Z, Nassar N, Badr L. The effectiveness of a pressure ulcer intervention program on the prevalence of hospital acquired pressure ulcers: controlled before and after study. Applied Nursing Research 2015; 28(2): 106-13.

34. Gunnigberg L. Risk, prevalence and prevention of pressure ulcers in three Swedish healthcare settings. J Wound Care 2004; 13(7): 286-90.

35. Woodbury MG, Houghton PE. Prevalence of pressure ulcers in Canadian healthcare settings. Ostomy Wound Manage 2004; 50(10): 22-38.

36. Duncan K. Preventing pressure ulcers. The Joint Commission Journal on Quality and Patient Safety 2007; 33(10): 605-610.

37. Gillespie BM, Chaboyer WP, Mcinnes E, Kent B, Whitty JA. Repositioning for pressure ulcer prevention in adults (protocol). Queensland: The Cochrane Collaboration and Wiley publishers, 2012; 2- 8 . 